\title{
Development of online hemodiafiltration in Japan
}

\author{
Hideki Kawanishi* ${ }^{*}$
}

\begin{abstract}
Evidence concerning online hemodiafiltration (ol-HDF) includes increased uremic toxin removal, prevention of dialysis-related hypotension, improved survival, and recovery of dialysis-related uncertain symptoms. In particular, evidence has been shown regarding prevention of dialysis hypotension and improvement of survival, but the mechanism of its manifestation is still unclear and its effects themselves are questionable. In Japan, pre dilution ol-HDF is mainly performed, and improvement in survival rate has been shown on the condition of convection volume is $40 \mathrm{~L} /$ session or more. In particular, the removal of a1-microglubulin ( $\mathrm{aMG}$ ), which is a medium-middle solute, is targeted. The antioxidant action (Heme Scavenger) of $\mathrm{aMG}$, is presumed, but in dialysis patients, the majority in serum are deteriorated (oxidized) aMG. It has been pointed out that removing the deteriorated aMG by ol-HDF may produce new aMG from the liver and lead to recovery of the original antioxidant effect. However, clinical evidence of this mechanism is desired. Obtaining evidence for the indicated $a \mathrm{MG}$ removal activity of ol-HDF will lead to advancement in HDF.
\end{abstract}

Keywords: Online HDF, Middle molecule, Convection volume, a1 microglubulin, Mortality

\section{Background}

Hemofiltration (HF) and hemodiafiltration (HDF) are used for the removal of middle molecular (MM) solutes of approximately $1 \mathrm{kDa}$ molecular weight (MW) per the middle molecular hypothesis that was proposed in the 1970s [1, 2]. HF is a method of dialysis therapy in which transmembrane pressure is applied to the filter and solutes are removed as a filtrate by convection, and the same volume of substitution fluid is added. HF simulates the glomerular function in the kidney and is effective for removing even large solutes. In addition, HF avoids the risk of disequilibrium syndrome as there are no acute changes in blood osmolarity. However, since the so-called renal tubular function is absent, the electrolyte and acidbase balance are adjusted by administering substitution fluid containing electrolytes and alkaline agents. Therefore, a strict balance between the convection volume

*Correspondence: h-kawanishi@tsuchiya-hp.jp Tsuchiya General Hospital, 3-30 Nakajima-cho, Naka-ku, Hiroshima 730-8655, Japan and substitution fluid volume is required. In particular, replacement with a large volume of fluid is necessary to obtain solute removal effects.

Thus, HF is excellent in removing middle to large solutes, but small solute removal comparable to that using hemodialysis (HD) is difficult using convection alone. Therefore, to improve small solute removal, dialysis (diffusion) is included in HDF [3-7]. In general, in HDF, the convective flow is lesser than the dialysate flow, which tends to lead to the misunderstanding that HF is added to compensate for the low removal ability of HD. However, considering the development process of HDF, it should be understood that $\mathrm{HD}$ is added to achieve the adequate removal of small solutes. Thus, HF was developed first, and HD was incorporated into it, resulting in HDF establishment. However, in basic HDF, the dialysate flow rate is $500-700 \mathrm{~mL} / \mathrm{min}$, which is the same as in HD. Therefore, in terms of efficiency, HDF represents the addition of HF to conventional HD. As a result, small solutes are rapidly removed, but the prevention of disequilibrium syndrome as the effect of HF cannot be expected.

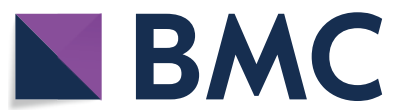

(c) The Author(s) 2021. Open Access This article is licensed under a Creative Commons Attribution 4.0 International License, which permits use, sharing, adaptation, distribution and reproduction in any medium or format, as long as you give appropriate credit to the original author(s) and the source, provide a link to the Creative Commons licence, and indicate if changes were made. The images or other third party material in this article are included in the article's Creative Commons licence, unless indicated otherwise in a credit line to the material. If material is not included in the article's Creative Commons licence and your intended use is not permitted by statutory regulation or exceeds the permitted use, you will need to obtain permission directly from the copyright holder. To view a copy of this licence, visit http://creativecommons.org/licenses/by/4.0/. The Creative Commons Public Domain Dedication waiver (http://creativeco mmons.org/publicdomain/zero/1.0/) applies to the data made available in this article, unless otherwise stated in a credit line to the data. 
A large amount of substitution fluid is required for stable large filtration HF/HDF. However, there is a limitation to the offline (bottle/back) method, and thus online HDF (ol-HDF) using a substitution fluid of aseptic/endotoxin-free membrane separation technology ws developed [3]. Currently, ol-HDF is generally replaced with 15-26 L (50-100 $\mathrm{mL} / \mathrm{min})$ for post-dilution and $24-72 \mathrm{~L}$ (100-300 $\mathrm{mL} / \mathrm{min}$ ) for pre-dilution, and it is high enough to obtain sufficient amount of substitution fluid. Increasing the blood flow rate and total dialysate volume is necessary to compensate for the decrease in actual dialysate volume. Therefore, HF is clinically useful for dialysisrelated distress syndromes, while the effects of HDF are due to improvement in removal efficiency. However, this increased removal efficiency does not produce adequate clinical differences when dialyzers themselves are highly efficient, and this aspect is important when evaluating the clinical significance of HDF.

\section{A new concept of middle molecule solute}

MM removal seems to begin with the following statement by Scriber BH at the American Society for Artificial Organs (ASAIO) in 1965 [8]. "The patients feel better on less dialysis, there is a chance that because the peritoneal membrane is leaky, we are removing with peritoneal dialysis certain higher molecular weight substances more efficiently than with hemodialysis, ......suggesting that we need a leaky membrane for a hemodialyzer". After that, the significance of MM was established by the "square meter-hour hypothesis [1]" and the "middle molecular hypothesis [2]" by Babb AL.

MM has been expanded to show an MW of $\geq 0.5 \mathrm{kDa}$ represented by $\beta 2$-microglobulin $(\beta M G)$ in recent years. Furthermore, with the development of dialyzer and advancements in HDF, further large molecular solutes can be included in MM. In a recent review,
MM was defined as a solute that passes through the glomerulus, with a MW of $0.5-58 \mathrm{kDa}$, which is the limit of glomerular filtration, and following revisions in $\mathrm{MM}$ classification were proposed "small-middle 0.5-15 kDa," "medium-middle $>15-25 \mathrm{kDa}$ " and "largemiddle $>25-58 \mathrm{kDa"} \mathrm{(Fig.} \mathrm{1)} \mathrm{[9].} \mathrm{In} \mathrm{the} \mathrm{future,} \mathrm{the}$ selection of blood purification therapy will follow this classification.

\section{Pre-dilution ol-HDF (pre-ol-HDF) and post-dilution ol-HDF (post-ol-HDF)}

In HDF, the removal characteristics differ depending on the dilution method. In post-ol-HDF, as the convection volume $(\mathrm{CV})$ increases, the removal of small-tolarge molecular solutes increases concurrently. When targeting small-MM solutes such as $\beta \mathrm{MG}$ (12 kDa), post-ol-HDF using a dialyzer with low protein leakage is effective. However, for a medium MM solute (for example, $\alpha 1$-microglobulin [ $\alpha \mathrm{MG}$ ], $33 \mathrm{kDa}$ ), a protein-leakage hemodiafilter must be used. However, it is difficult to separate albumin and $\alpha \mathrm{MG}$ on post-ol-HDF due to the excessive albumin leakage. In such cases, pre-ol-HDF that can separate albumin and $\alpha \mathrm{MG}$ can be selected. Although the biological activity of $\alpha \mathrm{MG}$ itself is not yet clear. In Japan, pre-ol-HDF using a protein leakage hemodiafilter to increase the removal efficiency up to $\alpha \mathrm{MG}$ has become the mainstream. On the other hand, in Europe, post-ol-HDF using a dialyzer with non-protein leakage to increase the efficiency of removing the MW up to $\beta \mathrm{MG}$ is the mainstream, for which uremic substance has been established as evidence. An increase in blood flow rate is essential for increasing CV in post-ol-HDF, and 300$400 \mathrm{~mL} / \mathrm{min}$ is common in Europe. In Japan, blood flow rate is $<300 \mathrm{~mL} / \mathrm{min}$ (average $250 \mathrm{~mL} / \mathrm{min}$ ), which is also one reason for choosing pre-ol-HDF (Fig. 1).

Pre dilution online HDF, albumin leakage membrane

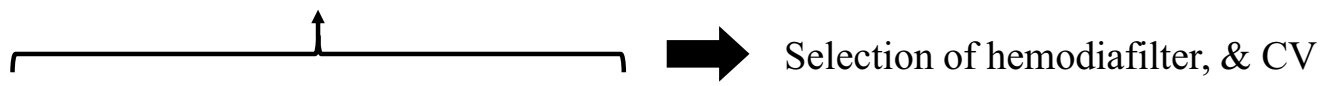

Post dilution online HDF, non-albumin leakage membrane

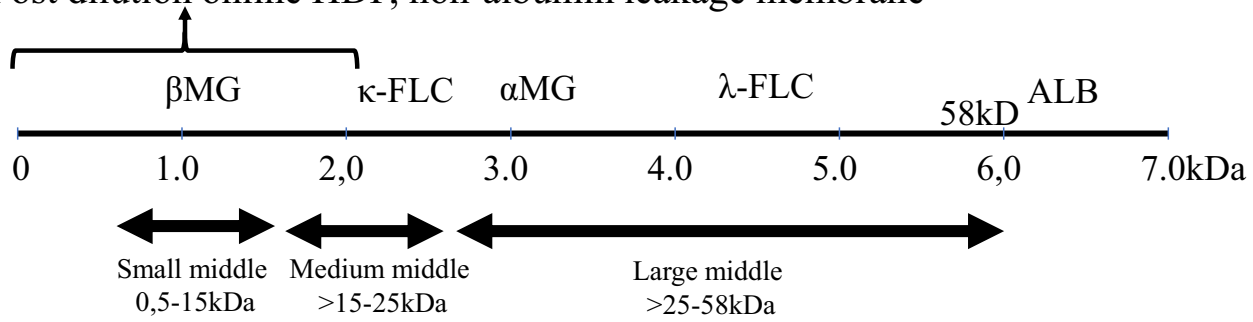

Fig. 1 The selection of dilution mode in online HDF base of the middle molecular solutes. $\beta$ MG: $\beta 2$-microglobulin, $\mathrm{k}$-FLC: $\mathrm{kfree-light-chains,} \lambda$-FLC: $\lambda$ free-light-chains, aMG: a1-microglobulin, HDF: hemodiafiltration 


\section{Clinical effects of HDF}

ol-HDF was developed to remove MM substances that cannot be completely removed using HD. Furthermore, substitution fluid is free from bacteria/endotoxins, and its source, dialysis fluid, should be ultrapure; this requirement may be achieved through the purification of dialysis fluid. Dialysis fluid purification has demonstrated several clinical effects, including reducing anemia, preventing dialysis-related amyloidosis, maintaining residual kidney function, improving nutritional status, and relieving dialysis-related hypotension, have been demonstrated [10-14].

Recent evidence has focused on increasing removal efficiency, preventing dialysis-related amyloidosis, hypotension, improving survival, and improving dialysis-related indefinite complaints. These effects may be additively exhibited through an ol-HDF-related increase in the removal efficiency. However, it is difficult to indicate the effects separately. Furthermore, the presence or absence of synergistic effects remains to be clarified [15]. The clinical effects and mortality according to symptom (observational study and randomized controlled trial [RCT]) are shown in Table 1 and Table 2, respectively.
Prevention of dialysis-related amyloidosis has been established [16, 17]. However, mechanisms underlying the prevention of dialysis-related hypotension and survival improvement are still not clear. Furthermore, the effects of HDF are debatable [18].

One clinical effect of HDF is the prevention of dialysisrelated hypotension. However, the volume of dialysate during HDF is larger than the amount of substitution fluid; therefore, the stabilization mechanism of circulatory dynamics observed in HF cannot be applied. This has been studied since the introduction of HDF. A recent study reported that dialysis-related hypotension could be reduced with pre-ol-HDF as well as pre HF [19]. Another study indicated that this effect occurred with post-olHDF [20]. RCTs and meta-analyses have proved the prevention of dialysis-related hypotension through ol-HDF [21]. However, although the Gibbs-Donnan effect [18] and low-temperature dialysis effect [22] was speculated, the mechanisms are not clear. Recently, Smith et al. conducted a randomized crossover study of high-flux HD (HFHD) and post-ol-HDF (CV $20 \mathrm{~L}$ ) involving 100 subjects following a blinded method and found no difference in recovery time after dialysis and significantly more

Table 1 Clinical effect of HDF, symptoms

\begin{tabular}{|c|c|c|c|}
\hline Study [Ref] & Study design & Modality/number & Results \\
\hline \multicolumn{4}{|l|}{ Dialysis related amyloidosis (DRA) } \\
\hline Locattelli [16], Lombardy/ltaly & Prospective obsevation & HDF (HF) versus LFHD:1082/6298, & DRA:42.2\%r reduction, Mortality:ns \\
\hline Nakai [17], Japan & Retrospective obsevation & HDF 77 versus LFHD (total 1192) & DRA 97\% reduction $P<0.0001$ \\
\hline \multicolumn{4}{|l|}{ Dialysis related hypotension $(D R H)$} \\
\hline Locattelli [19], Italian study & $\mathrm{RCT}$ & $\begin{array}{l}\text { Pre-ol-HF/HDF versus LFHD: } \\
\text { 150/75/75 }\end{array}$ & DRH 54\% reduction \\
\hline ESHOL study [20], Catalonian/Spain & RCT sub-analysis & Post-ol-HDF versus HFHD: 450/456 & DRH 28\% reduction \\
\hline Donauer [22], Germany & Crossover, single center & $\begin{array}{l}\text { Post-ol-HDF versus Cool HD: } 25 \text { ses- } \\
\text { sion }\end{array}$ & $\begin{array}{l}\text { DRH: prevention as same as post-ol- } \\
\text { HDF \& Cool HD }\end{array}$ \\
\hline Smith [23], Glasgow/UK & Crossover, blind, single center & Post-ol-HDF versus HFHD: 50 & $\begin{array}{l}\text { Recovery time: longer } \\
\text { DRH: } 52 \% \text { higher }\end{array}$ \\
\hline \multicolumn{4}{|l|}{ Anemia } \\
\hline Locattelli [36], Italian study & RCT sub-analysis & $\begin{array}{l}\text { Pre-ol-HF/HDF versus LFHD: } \\
\text { 150/75/75 }\end{array}$ & ns \\
\hline Pedrini [37], Italy, Czech, Slovenia, & Retrospective cohort & $\begin{array}{l}\text { mixed dilusion HDF versus post-ol- } \\
\text { HDF; } 87 / 87\end{array}$ & Mixed HDF:Hgb up $(p=0.0124)$ \\
\hline \multicolumn{4}{|l|}{ Quality of life (QOL) } \\
\hline Karkar [38], Saudi Arabia & $\mathrm{RCT}$ & Post-ol-HDF versus HFHD:32/32 & Better \\
\hline \multicolumn{4}{|l|}{ Restless legs syndrome $(R L S)$} \\
\hline Sakurai 2013 [45], Japan & Retrospective, observation & Pre-ol-HDF 17 & $\begin{array}{l}\text { RLS prevention: aMG removal } \\
\text { rate }>35 \%\end{array}$ \\
\hline \multicolumn{4}{|l|}{ Inflammation } \\
\hline Ariza [34], Spain & Crossover study & $\begin{array}{l}\text { HFHD versus post-ol-HDF versus mid- } \\
\text { dilution HDF:12 }\end{array}$ & HDF: decrease CD14, CD16, monocyte \\
\hline $\begin{array}{l}\text { Dutch CONTRAST [35], The Nether- } \\
\text { lands }\end{array}$ & RCT sub-analysis & Post-ol-HDF versus LFHD: 356/358 & Decease CRP \\
\hline
\end{tabular}


Table 2 Clinical effect of HDF, mortality

\begin{tabular}{|c|c|c|c|}
\hline Study [Ref] & Study design & Modality/number & Results \\
\hline \multicolumn{4}{|l|}{ Observation study } \\
\hline $\begin{array}{l}\text { Canaud [24] } \\
\text { (Euro-DOPPS-1) Germany, France, Italy, } \\
\text { Spain, UK }\end{array}$ & Prospective obsevation & $\begin{array}{l}\text { LFHD } 1366(63 \%), \\
\text { HFHD } 546(25.2 \%) \\
\text { Low-HDF } 156(7.2 \%) \\
\text { High-HDF } 97(4.5 \%)\end{array}$ & $\begin{array}{l}\text { High-HDF versus LFHD: mortality redac- } \\
\text { tion } 35 \%\end{array}$ \\
\hline $\begin{array}{l}\text { Panichi [25] } \\
\text { (RISCAVID), Italy }\end{array}$ & Prospective obsevation & $\begin{array}{l}\text { LFHD } 424(56 \%) \\
\text { ol-HDF } 129(17.7 \%) \\
\text { off-HDF } 204(27 \%)\end{array}$ & $\begin{array}{l}\text { ol-HDF versus LFHD: mortality redaction } \\
22 \%\end{array}$ \\
\hline Vilar [26], UK & Retrospective & $\begin{array}{l}\text { HFHD } 626 \\
\text { ol-HDF 232(27\%) }\end{array}$ & $\begin{array}{l}\text { ol-HDF versus HFHD: mortality redaction } \\
34 \%\end{array}$ \\
\hline $\begin{array}{l}\text { European Clinical Database (EUCLID) } \\
\text { [27], Czech, France, Italy, Portugal, } \\
\text { Romania, Spain, Turkey }\end{array}$ & Retrospective & $\begin{array}{l}\text { Post-ol HDF CV < 54.6L/wk ver- } \\
\text { sus > 64.8L/wk: 204/204 }\end{array}$ & $\begin{array}{l}\text { CV > } 70.1 \text { L/wk:survival } 64 \% \text { increase } \\
\text { Survival and CRP/ } \beta 2 M G \text { reduction } \\
\text { depend on CV }\end{array}$ \\
\hline $\begin{array}{l}\text { Euro-DOPPS [31] } \\
\text { (DOPPS-4,5), Sweden, France, Belgium, } \\
\text { Italy, UK, Spain, Germany }\end{array}$ & Prospective obsevation & Post-ol-HDF versus HD: 2012/6555 & ns \\
\hline Kikuchi [32], JRDR, Japan & Retrospective & $\begin{array}{l}\text { Pre-ol-HDF } \geq 40 \mathrm{~L} \text { session versus }<40 \mathrm{~L} \& \\
\text { HD: } 2548 / 2424 / 5000\end{array}$ & $\begin{array}{l}\text { Pre-ol-HDF } \geq 40 \mathrm{~L} \text { : mortality redaction } \\
29.1 \%\end{array}$ \\
\hline \multicolumn{4}{|l|}{ Randomized controlled trial (RCT) } \\
\hline Dutch CONTRAST [28], The Netherlands & $\mathrm{RCT}$ & Post-ol-HDF versus LFHD: 356/358 & ns, higher CV (> 21.95L):reduction 38\% \\
\hline Turkish study [29], Turkey & $\mathrm{RCT}$ & Post-ol-HDF versus HFHD: 391/391 & $\begin{array}{l}\text { ns, higher CV (> 17.4L): mortality reduc- } \\
\text { tion } 46 \%\end{array}$ \\
\hline ESHOL study [20], Spain & $\mathrm{RCT}$ & Post-ol-HDF versus HFHD: 450/456 & $\begin{array}{l}\text { Mortality Reduction 30\%, higher CV (23- } \\
25 \mathrm{~L}): 40 \%, \mathrm{CV}(>25 \mathrm{~L}): 45 \%\end{array}$ \\
\hline French study [30], France & $\mathrm{RCT}$ & $\begin{array}{l}\text { Post-ol-HDF versus HFHD, > 65y.o: } \\
190 / 191\end{array}$ & ns \\
\hline
\end{tabular}

HDF, hemodiafiltration; LFHD, low flux hemodialysis; HFHD, high flux hemodialysis; post-ol-HDF, post dilution online HDF; pre-ol-HDF, pre dilution online HDF; CV, convection volume

dialysis hypotension with HDF [23]. The fact that the superiority of HDF was denied in a strict crossover study such as this is an objection to the prevention of dialysisrelated hypotension.

To overcome the limitations of previous observation studies [24-27] for survival, large RCTs have been conducted in Europe, such as the Dutch CONTRAST [28] (comparison between post-ol-HDF and low flux HD [LFHD]), the Turkish Study [29], the ESHOL study [20], and the French study [30] (the latter three compared post-ol-HDF and HFHD). These RCTs showed similar results, indicating that post-HDF with high-CV have a favorable influence on survival rates. However, a high blood flow rate is essential for obtaining a high $\mathrm{CV}$ with post-ol-HDF, suggesting that survival rates were good when a high blood flow rate could be obtained.

A recent clinical study involved an analysis of survival with HDF using Euro-DOPPS 4-5 [31]. Unlike the study using Euro-DOPPS 1 [24], the superiority of HDF was not shown. However, as the research and analysis styles were comparable, the effects of HDF on survival are not established..

In Japan, pre-ol-HDF is used for $90 \%$ of patients. Therefore, the Japanese Renal Data Registry (JRDR) compares the 1-year prognosis of pre-ol-HDF and HD using the propensity score-matched method based on the national database [32]. Pre-ol-HDF with a higher $\mathrm{CV}(\geq 40 \mathrm{~L})$ decreased all-cause mortality and cardiovascular diseases (CVD) mortality unlike HD or HDF with a small CV. These RCTs and observational studies have shown the efficacy of ol-HDF for survival, but its superiority is small. The hazard ratio (HR) in the "pooled individual participant data analysis," which was analyzed by combining all the cases of CONTRAST, Turkish Study, ESHOL study, and French study, was 0.86 (CI 0.75-0.99), which is close to 1.0 [33].

Factors of clinical efficacy of ol-HDF include improving dialysis-related indefinite complaints. In particular, it is expected to be effective for restless legs syndrome (RLS), pruritus, inflammation control, and quality of life (QOL).

Regarding inflammation control in ol-HDF, in a crossover study by HFHD and post-ol-HDF/mid-dilution HDF, ol-HDF reduced the expression of CD14, CD16 on the surface of monocyte and decreased endothelial microparticles [34]. In addition, Duch-CONTRAST [35] and EUCLID study [27] also showed a decrease in C-reactive protein (CRP) levels. Therefore, it can be inferred that 
ol-HDF led to controlled inflammation and improved survival rate.

The effect of HDF on improving anemia has also been discussed. It was denied in the sub-analysis of the Italian study by Locatelli et al. [36]. In a recent comparison between post-ol-HDF and mixed-ol-HDF, mixed-ol-HDF showed an increase in hemoglobin [37], but the mechanism is unclear.

Regarding QOL, an RCT from Saudi Arabia migrated patients controlled by low flux HD (LFHD) to HFHD or ol-HDF using the same dialyzer, and ol-HDF not only has good solute removal but also well QOL evaluated by KDQOL-SF [38].

Based on the evidence of the clinical effects of HDF, the guidelines prepared by the Japanese Society for Dialysis Therapy (JSDT) also recommend the following: "HDF should be considered as a measure against indefinite complaints (itchiness, arthralgia, malaise, loss of appetite, etc.) and dialysis-related hypotension in patients who do not improve HFHD" [39].

\section{Japanese online HDF}

Canaud et al. reported on the "Global trends in HDF", which shows that Japan has the highest HDF patients as of 2017 [40].

Although in Japan, ol-HDF started in 1993, concerning payment for medical services, inaccurate circumstances persisted [15]. At the beginning of 2010, an ol-HDF machine for a central dialysis fluid delivery system was approved as a multi-purpose dialysis system, thus ol-HDF became a general procedure in dialysis therapy. After the revision of the reimbursement for medical services in
2012, a technical fee for ol-HDF was newly established and separated from off-HDF. This was the first time a technical fee was established for ol-HDF in the world. Furthermore, as a facility requirement, the "maintaining dialysis fluid quality [41]" was added. In particular, it became possible to maintain dialysis fluid quality in all patients (including those undergoing HD) in facilities in which the ol-HDF system is maintained. Moreover, the use of an approved "hemodiafilter" is required for olHDF to be reimbursed. Furthermore, there are no restrictions on indications in terms of medical fees, and it can be used for all dialysis patients. Since then, the number of HDF patients has increased rapidly, reaching 144,717 (43.5\% of HD patients) at the end of 2019 (Fig. 2). In particular, $\geq 90 \%$ of ol-HDF is pre-ol-HDF. The reasons why pre-ol-HDF became mainstream in Japan are as follows: (1) Relatively low blood flow (average $224 \mathrm{~mL} / \mathrm{min}$ ) [42] and failure to achieve high CV post-ol-HDF; (2) Since the target substance to be removed was $\alpha 1 \mathrm{MG}$ with a MW of $33 \mathrm{kDa}$, a protein leakage hemodiafilter was used to measure the separation of albumin and $\alpha 1 \mathrm{MG}$. Recently, use of post-ol-HDF has been gradually increasing.

\section{What is a1-microglobulin, a recent topic about HDF in Japan?}

There are many reviews on the clinical effects of HDF $[18,40,43]$. A recent topic is the improvement of survival by higher CV in Europe [20, 27-30,33]. In addition, many studies suggest that post-ol-HDF improves survival proportional to the increase in CV $(>18-24 \mathrm{~L})$ [40]. However, although the amount of CV is shown in these studies, the target solute removal is not shown.

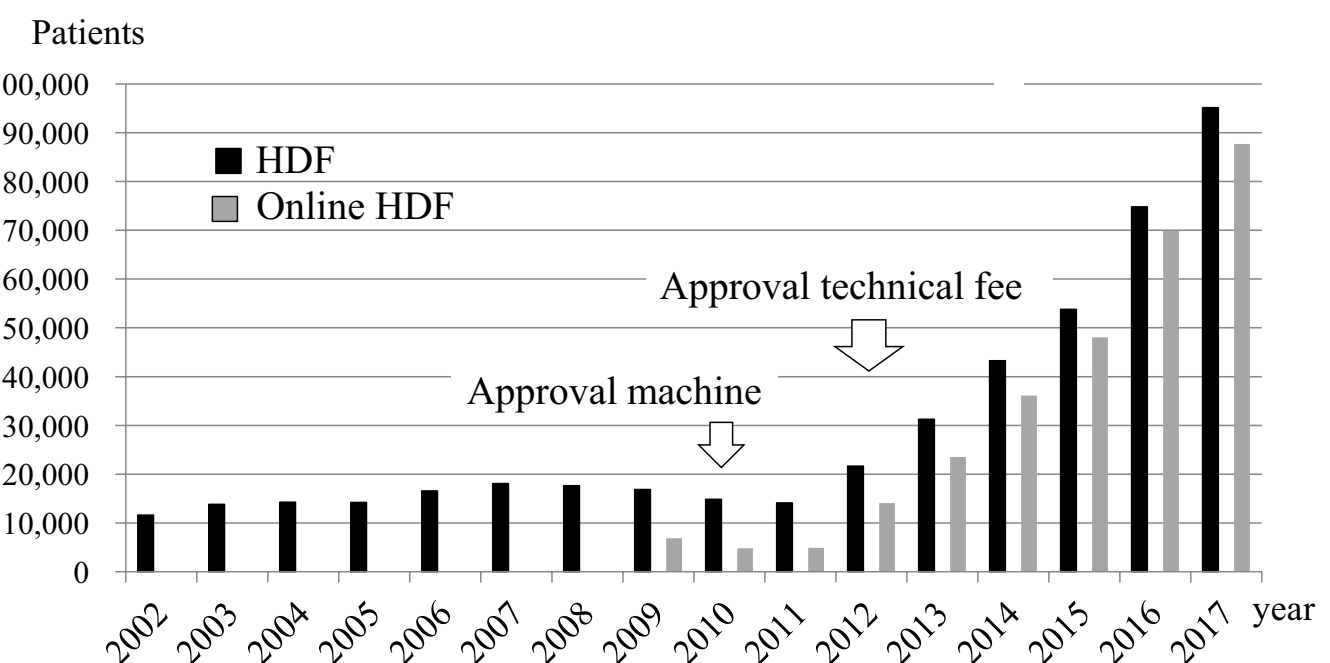

Fig. 2 Changes of HDF in Japan, data from JRDR. Black bar: patient's number of total HDF, gray bar: on-line HDF (include I-HDF), approval HDF machine at 2010 and technical fee in national reimbursement at 2012. HDF: hemodiafiltration, JRDR, Japanese Renal Data Registry 
Therefore, the theoretical relationship between the survival and the increase of solute removal is unclear. Also, the upper limit of the $\mathrm{CV}$ is not presented.

Pre-ol-HDF in Japan specifically aims to remove $\alpha \mathrm{MG}$, and Sakurai et al. reported that achieving high efficiency of $\alpha \mathrm{MG}$ removal rate of $\geq 35-40 \%$ resulted in improvement of RLS [44]. Therefore, it is clinically significant that this target has been determined. At present, the goal is to set therapeutic conditions that maximize the removal of $\alpha$ MG while suppressing albumin leakage ( $\leq 5 \mathrm{~g} /$ session). Sakurai et al. [45], showed that an excessive increase in the removal volume can be obtained even with a slight increase in the removal rate in the higher removal rate region (Fig. 3). Furthermore, according to the JRDR, a pre-ol-HDF with $a \geq 40 \mathrm{~L}$ substitution fluid volume improved the 1-year survival rate. The substitution fluid volume that most contributed to the survival rate was $50.5 \mathrm{~L}$ pre-ol-HDF, which is the prognosis of survival [32]. It was shown that a U-shaped curve is estimated in relation to the amount of substitution fluid. Sakurai et al. also showed that high-efficiency HDF releases the platelet surface marker CD62P, suggesting the stress on blood cell components [46]. From this result, the conditions of blood flow $250-300 \mathrm{~mL} / \mathrm{min}$ and substitution fluid volume $200-240 \mathrm{~mL} / \mathrm{min}(48-58 \mathrm{~L} /$ session $)$ are recommended for pre-ol-HDF in Japan (Table 3). However, the
Table 3 Characteristics of standard online HDF in Japan

\section{Pre-dilution online HDF}

Blood flow rate: $200-250 \mathrm{~mL} / \mathrm{min}$

Substitution fluid volume: $48-60 \mathrm{~L} / \mathrm{session}$

Dialysate flow: $500-600 \mathrm{~mL} / \mathrm{min}$

Dialysis time: $4-5 \mathrm{~h}$

Hemodiafilter: protein leakage member

Mainly central dialysate delivery system

Target removal rate of $a \mathrm{MG} 35-40 \%$ and $\beta \mathrm{MG} 80 \%$

functions of $\alpha \mathrm{MG}$ are not clear, and until recently, it was regarded as a marker for MM.

One of the founders of ol-HDF in Japan, Kim ST, explained the significance of $\alpha \mathrm{MG}$ removal [47]. In serum, the ratio of free form and high molecular IgA bound form $\alpha \mathrm{MG}$ is almost same, and the target of removal is about $50 \%$ free form $\alpha \mathrm{MG}$. Therefore, the removal rate per HDF is limited to $60 \%$. As its physiological function, both cell differentiation inhibitory action and antioxidant action (Heme Scavenger) $[48,49]$ are presumed. Nevertheless, in dialysis patients, the serum concentration $\alpha \mathrm{MG}$ is more than ten times higher than normal, and most of them are deteriorated (oxidized)

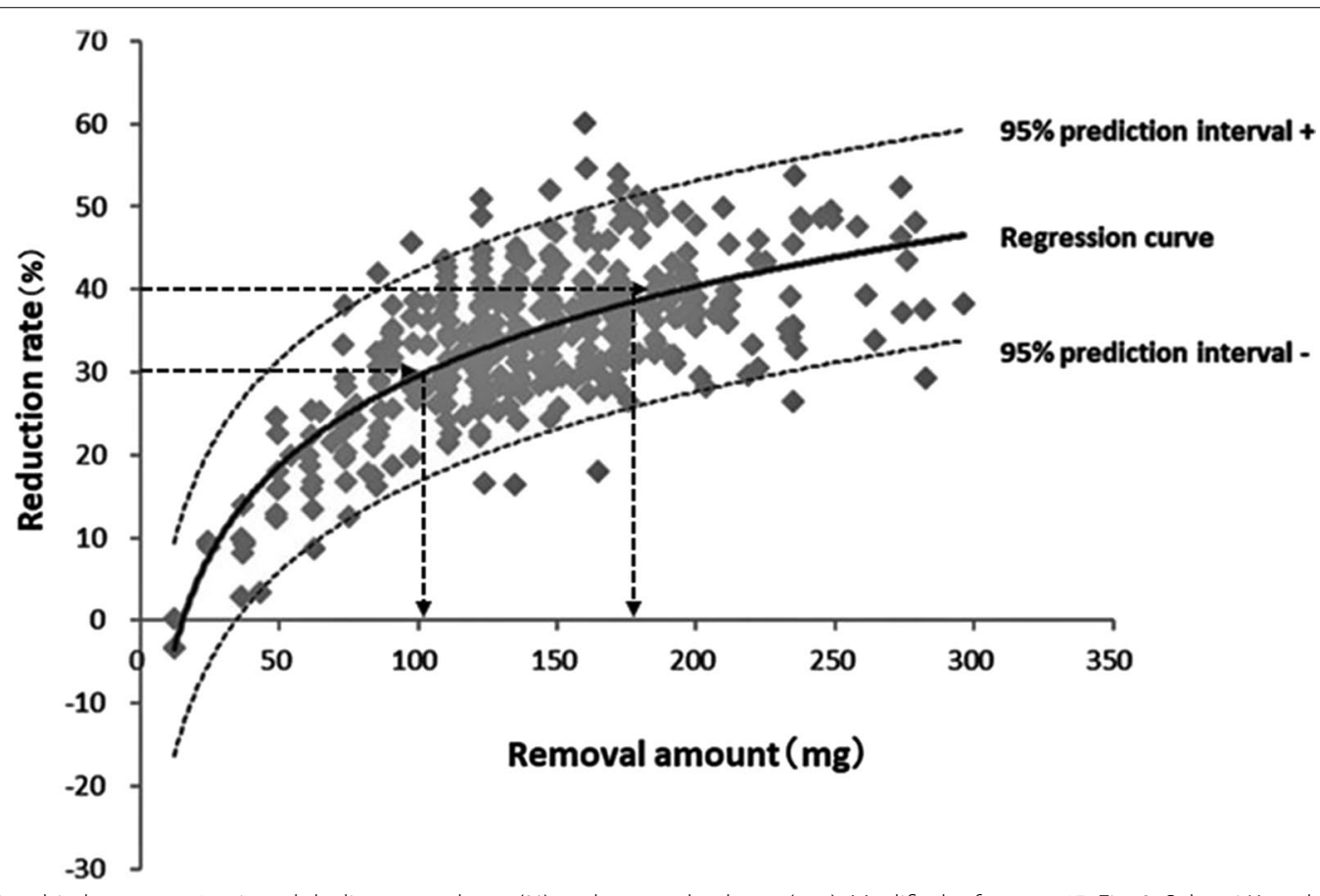

Fig. 3 Relationship betweena1-microglobulin removal rate (\%) and removal volume (mg). Modified reference 45, Fig. 3, Sakurai K et al., Renal Replacement Therapy 2021 with consent from the author. This graph shows that an excessive increase in the removal volume (mg) can be obtained even with a slight increase in the removal rate (\%) in the higher removal rate region 
$\alpha \mathrm{MG}$. Therefore, it is presumed that the turnover is also suppressed. It has been suggested that removing the deteriorated $\alpha \mathrm{MG}$ through HDF may produce new $\alpha \mathrm{MG}$ from the liver and aid recovery of the original antioxidant effect (Fig. 4). However, clinical evidence of this mechanism is required.

A prospective observational cohort study "Lapanese Study of the effects of AMG ( $\alpha 1$-microglobulin) reduction rates on the survival, complications, and prognosis in dialysis patients (JAMREDS)" has been started to prove the clinical efficacy of $\alpha \mathrm{MG}$ removal, led by the Japanese Society for HDF (Fig. 5) [50]. This study includes 4000 uncomplicated outpatients with HD at a registered facility for 3 years to examine the relationship between $\alpha \mathrm{MG}$ removal rate and prognosis. The dialysis modality includes all HD and HDF. It is expected that the relationship between MM removal efficiency and prognosis will be clarified by investigating the prognosis of dialysis patients and CVD events.

\section{Intermittent Infusion Hemodiafiltration (I-HDF)}

I-HDF was developed in Japan as a division of ol-HDF and accounted for about $27 \%$ of ol-HDF. It is mainly positioned to prevent complications, i.e., dialysis related-hypotension and correcting peripheral circulatory disorders by HD itself [51, 52].

By systematically replenishing the blood side with purified dialysate or substitution fluid, blood pressure can be maintained by suppressing hypovolemia due to body water removal, and plasma refilling rate (PRR) can be achieved by improving peripheral circulation. Furthermore, it is thought to be effective in reducing the number of treatments for hypotension during HD by increasing the amount and promoting the movement of fluid from the interstitial space to the blood vessels.

I-HDF using back-filtration and replenished ultrapure dialysate through the membrane can suppress the gradual decrease in membrane performance. The standard I-HDF is replenished seven times every $30 \mathrm{~min}$ of substitution fluid $200 \mathrm{~mL}$, and the total amount of $1.4 \mathrm{~L}$, and filter the amount of replenisher fluid + body water at times other than the time of replenishment (Fig. 6). It is positioned as an ol-HDF for a small amount of replacement. Although ol-HDF has been shown to prevent dialysis-related hypotension, further studies are needed to clarify its other effects.

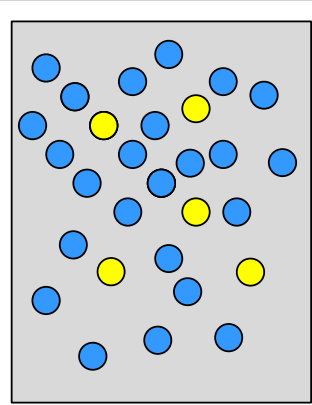

HD patients

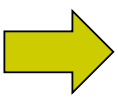

HDF

Fig. 4 Theoretical mechanism of a1-microglobulin removal by HDF. aMG physiological function, both cell differentiation inhibitory action and antioxidant action (Heme Scavenger) are presumed, but in dialysis patients, the serum concentration of aMG is > 10 times higher than normal, and the majority of them are a deteriorated (oxidized) $a \mathrm{MG}$. It is presumed that turnover is also suppressed. It has been pointed out that removing the deteriorated $a \mathrm{MG}$ by HDF may produce new $\mathrm{MMG}$ from the liver and recovery the original antioxidant effect. HDF, hemodiafiltration

\begin{tabular}{|c|c|c|c|}
\hline 2021 & 2021 & 2022 & 2023 \\
\hline \multirow{3}{*}{$\begin{array}{l}50 \text { facilities } \\
4000 \text { cases }\end{array}$} & \multicolumn{3}{|c|}{$\alpha M G$ removal rate } \\
\hline & \multicolumn{3}{|c|}{ CVD Event } \\
\hline & & tality & \\
\hline
\end{tabular}

Fig. 5 Scheme of JAMREDS Study. A prospective observational cohort study "Japanese Study of the effects of AMG (a1-micoroglobulin) reduction rates on the survival, complications, and prognosis in dialysis patients 


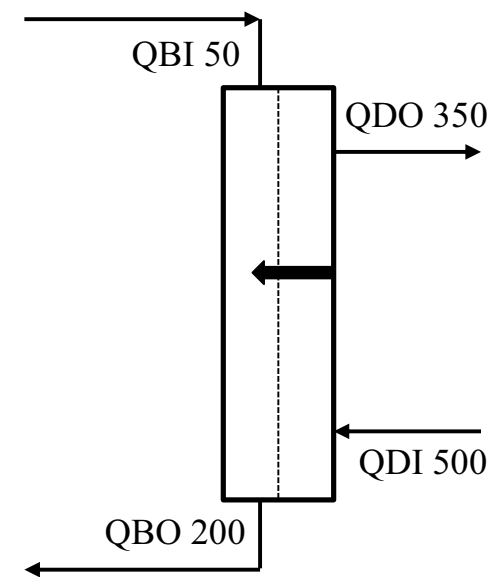

Intermittent infusion mode

Infusion back filtration $200 \mathrm{~mL}, 150 \mathrm{~mL} / \mathrm{min}$

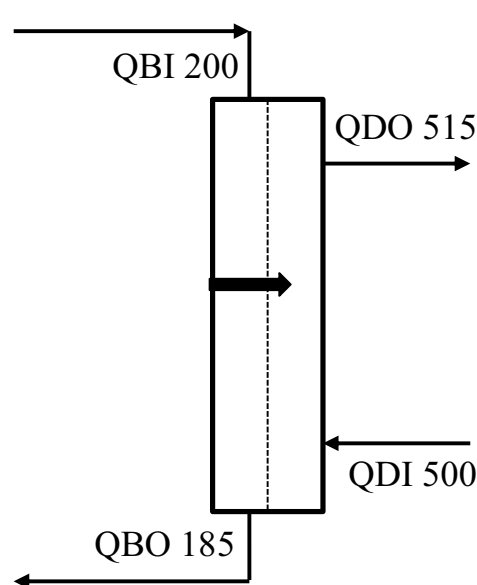

\section{Ultrafiltration mode}

\section{Ultrafiltrate}

Back filtration fluid + body water removal

Fig. 6 Intermittent Infusion Hemodiafiltration (I-HDF). The standard I-HDF is replenished seven times every 30 min of substitution fluid $200 \mathrm{~mL}$, and the total amount of $1.4 \mathrm{~L}$, and filter the amount of replenisher fluid + body water at times other than the time of replenishment (Rif.52)

\section{Conclusions}

Evidence of the effectiveness for ol-HDF is gradually accumulating. Although dialysis amyloidosis has been established, the prevention of dialysis-related hypotension and dialysis-related indefinite challenges remains unclear. Moreover, the apparent benefit for survival has not yet been determined. The prescription of ol-HDF varies from country to country and each facility, including the selection of hemodiafilter. Obtaining sufficient evidence for $\alpha \mathrm{MG}$ removal by ol-HDF will lead to further advancement in HDF.

\section{Abbreviations}

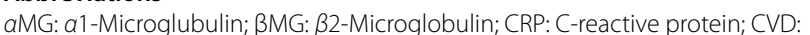
Cardiovascular diseases; DRA: Dialysis related amyloidosis; DRH: Dialysis related hypotension; HD: Hemodialysis; HFHD: High flux Hemodialysis; HF: Hemofiltration; HDF: Hemodiafiltration; I-HDF: Intermittent infusion hemodiafiltration; JRDR: Japanese Renal Data Registry; LFHD: Low flux hemodialysis; MW: Molecular weight; MM: Middle molecular; ol-HDF: Online hemodiafiltration; off-HDF: Offline hemodiafiltration; pre-ol-HDF: Pre-dilution online hemodiafiltration; post-ol-HDF: Post-dilution online hemodiafiltration; QOL: Quality of life; RCT: Randomized controlled trial; RLS: Restless legs syndrome.

\section{Acknowledgements}

Not applicable.

\section{Authors' contributions}

HK contributed to the intellectual discussion during manuscript drafting, revision, and the approval of the final version.

\section{Funding}

None.

\section{Availability of data and materials} Not applicable.

\section{Declarations}

Ethics approval and consent to participate

Not applicable.

\section{Consent for publication}

Not applicable.

\section{Competing interests}

The author declares that they have no competing interests.

Received: 25 June 2021 Accepted: 16 September 2021

Published online: 02 October 2021

\section{References}

1. Babb AL, Popovich RP, Christopher TG, Scribner BH. The genesis of the square meter-hour hypothesis. Trans Am Soc Artif Intern Organs. 1971:17:81-91.

2. Babb AL, Ahmad S, Bergström J, Scribner BH. The middle molecule hypothesis in perspective. Am J Kidney Dis. 1981;1:46-50.

3. Henderson LW, Besarab A, Michaels A, Bluemle LW Jr. Blood purification by ultrafiltration and fluid replacement (diafiltration). Trans Am Soc Artif Intern Organs. 1967;13:216-26.

4. Henderson LW, Sanfelippo ML, Beans E. 'On-line' preparation of sterile pyrogen-free electrolyte solution. Trans Am Soc Artif Intern Organs. 1978;24:465-7.

5. Henderson L. Current status of hemofiltration. Artif Organs. 1978;2(suppl):11-5.

6. Asaba H, Bergström J, Fürst $P$, Lindh $K$, Mion C, Oulès R, et al. Sequential ultrafiltration and diffusion as alternative to conventional hemodialysis. Proc Clin Dial Transplant Forum. 1976;6:129-35.

7. Leber HW, Wizemann V, Goubeaud G, Rawer P, Schütterle G. Hemodiafiltration: a new alternative to hemofiltration and conventional hemodialysis. Artif Organs. 1978;2(suppl):408-11.

8. Scriber BH. Discussion. Trans Am Soc Artif Int Organs. 1965;11:29.

9. Rosner M, Reis T, Husain-Syed F, Vanholder R, Hutchison C, Stenvinkel P, et al. Classification of uremic toxins and their role in kidney failure. Clin J Am Soc Nephrol. 2021. https://doi.org/10.2215/CJN.02660221. 
10. Baz M, Durand C, Ragon A, Jaber K, Andrieu D, MerzoukT, et al. Using ultrapure water in hemodialysis delays carpal tunnel syndrome. Int J Artif Organs. 1991;14:681-5.

11. Sitter T, Bergner A, Schiff H. Dialysate related cytokine induction and response to recombinant human erythropoietin in haemodialysis patients. Nephrol Dial Transplant. 2000;15:1207-11.

12. McKane W, Chandna SM, Tattersall JE, Greenwood RN, Farrington K. Identical decline of residual renal function in high-flux biocompatible hemodialysis and CAPD. Kidney Int. 2002;61:256-65.

13. Schiffl H, Lang SM, Fischer R. Ultrapure dialysis fluid slows loss of residual renal function in new dialysis patients. Nephrol Dial Transplant. 2002;17:1814-8

14. Izuhara Y, Miyata T, Saito K, Ishikawa N, Kakuta T, Nangaku M, et al. Ultrapure dialysate decreases plasma pentosidine, a marker of'carbonyl stress.' Am J Kidney Dis. 2004;43:1024-9.

15. Kawanishi $\mathrm{H}$. What can we expect from on-line hemodiafiltration? Blood Purif. 2013;35(suppl 1):1-5.

16. Locatelli F, Marcelli D, Conte F, Limido A, Malberti F, Spotti D. Comparison of mortality in ESRD patients on convective and diffusive extracorporeal treatments. Kidney Int. 1999:55:286-93.

17. Nakai S, Iseki K, Tabei K, Kubo K, Masakane I, Fushimi K, et al. Outcomes of hemodiafiltration based on Japanese dialysis patient registry. Am J Kidney Dis. 2001;38(4 Suppl 1):S212-6.

18. Kawanishi $\mathrm{H}$. Is there enough evidence to prove that hemodiafiltration is superior? Blood Purif. 2018:46:3-6.

19. Locatelli F, Altieri P, Andrulli S, Bolasco P, Sau G, Pedrini LA, et al. Hemofiltration and hemodiafiltration reduce intradialytic hypotension in ESRD. $J$ Am Soc Nephrol. 2010;21:1798-807.

20. Maduell F, Moreso F, Pons M, Ramos R, Mora-Macià J, Carreras J, et al. High-efficiency postdilution online hemodiafiltration reduces all-cause mortality in hemodialysis patients. J Am Soc Nephrol. 2013:24:487-97.

21. Nistor I, Palmer SC, Craig JC, Saglimbene V, Vecchio M, Covic A, et al. Convective versus diffusive dialysis therapies for chronic kidney failure: an updated systematic review of randomized controlled trials. Am J Kidney Dis. 2014;63:954-67.

22. Donauer J, Schweiger C, Rumberger B, Krumme B, Böhler J. Reduction of hypotensive side effects during online-haemodiafiltration and low temperature haemodialysis. Nephrol Dial Transplant. 2003;18:1616-22.

23. Smith JR, Zimmer N, Bell E, Francq BG, McConnachie A, Mactier R. A randomized, single-blind, crossover trial of recovery time in high-flux hemodialysis and hemodiafiltration. Am J Kidney Dis. 2017;69:762-70.

24. Canaud B, Bragg-Gresham JL, Marshall MR, Desmeules S, Gillespie BW, Depner T, et al. Mortality risk for patients receiving hemodiafiltration versus hemodialysis: European results from the DOPPS. Kidney Int. 2006;69:2087-93.

25. Panichi V, Rizza GM, Paoletti S, Bigazzi R, Aloisi M, Barsotti G, et al. Chronic inflammation and mortality in haemodialysis; effect of different renal replacement therapies. Results from the RISCAVID study. Nephrol Dial Transplant. 2008:23:2337-43.

26. Vilar E, Fry AC, Wellsted D, Tattersall JE, Greenwood RN, Farrington K. Long-term outcomes in online hemodiafiltration and high-flux hemodialysis: a comparative analysis. Clin J Am Soc Nephrol. 2009;4:1944-53.

27. Canaud B, Barbieri C, Marcelli D, Bellocchio F, Bowry S, Mari F, et al. Optimal convection volume for improving patient outcomes in an international incident dialysis cohort treated with online hemodiafiltration. Kidney Int. 2015;88:1108-16.

28. Grooteman MP, van den Dorpel MA, Bots ML, Penne EL, van der Weerd NC, Mazairac AH, et al. Effect of online hemodiafiltration on all-cause mortality and cardiovascular outcomes. J Am Soc Nephrol. 2012;23:1087-96.

29. Ok E, Asci G, Toz H, Ok ES, Kircelli F, Yilmaz M, et al. Mortality and cardiovascular events in online haemodiafiltration (OL-HDF) compared with high-flux dialysis: results from the Turkish OL-HDF Study. Nephrol Dial Transplant. 2013;28:192-202.

30. Morena M, Jaussent A, Chalabi L, Leray-Moragues $H$, Chenine L, Debure $A$, et al. Treatment tolerance and patient-reported outcomes favor online hemodiafiltration compared to high-flux hemodialysis in the elderly. Kidney Int. 2017;91:1495-509.

31. Locatelli F, Karaboyas A, Pisoni RL, Robinson BM, Fort J, Vanholder R, et al. Mortality risk in patients on hemodiafiltration versus hemodialysis: a "real-world" comparison from the DOPPS. Nephrol Dial Transplant. 2018;1(33):683-9.

32. Kikuchi K, Hamano T, Wada A, Nakai S, Masakane I. Predilution online hemodiafiltration is associated with improved survival compared with hemodialysis. Kidney Int. 2019;95:929-38.

33. Peters SA, Bots ML, Canaud B, Davenport A, Grooteman MP, Kircelli F, et al. HDF pooling project investigators haemodiafiltration and mortality in end-stage kidney disease patients: a pooled individual participant data analysis from four randomized controlled trials. Nephrol Dial Transplant. 2016:31:978-84.

34. Ariza F, Merino A, Carracedo J, Alvarez de Lara MA, Crespo R, Ramirez R, et al. Post-dilution high convective transport improves microinflammation and endothelial dysfunction independently of the technique. Blood Purif. 2013:35(4):270-8.

35. den Hoedt CH, Bots ML, Grooteman MP, van der Weerd NC, Mazairac AH, Penne EL, et al. Online hemodiafiltration reduces systemic inflammation compared to low-flux hemodialysis. Kidney Int. 2014;86:423-32.

36. Locatelli F, Altieri P, Andrulli S, Sau G, Bolasco P, Pedrini LA, et al. Predictors of haemoglobin levels and resistance to erythropoiesis-stimulating agents in patients treated with low-flux haemodialysis, haemofiltration and haemodiafiltration: results of a multicentre randomized and controlled trial. Nephrol Dial Transplant. 2012;27:3594-600.

37. Pedrini LA, Zawada AM, Winter AC, Pham J, Klein G, Wolf M, et al. Effects of high-volume online mixed-hemodiafiltration on anemia management in dialysis patients. PLoS ONE. 2019;22(14):e0212795.

38. Karkar A, Abdelrahman M, Locatelli F. A randomized trial on healthrelated patient satisfaction level with high-efficiency online hemodiafiltration versus high-fux dialysis. Blood Purif. 2015;40:84-91.

39. Watanabe Y, Kawanishi H, Suzuki K, Nakai S, Tsuchida K, Tabei K, et al. Maintenance hemodialysis: hemodialysis prescriptions" Guideline Working Group, Japanese Society for Dialysis Therapy Japanese Society for dialysis therapy clinical guideline for "Maintenance hemodialysis: hemodialysis prescriptions. Ther Apher Dial. 2015;19(Suppl 1):67-92.

40. Canaud B, Köhler K, Sichart JM, Möller S. Global prevalent use, trends and practices in haemodiafiltration. Nephrol Dial Transplant. 2020;35:398-407.

41. Mineshima M, Kawanishi H, Ase T, Kawasaki T, Tomo T, Nakamoto H. 2016 Update Japanese Society for Dialysis Therapy Standard of fluids for hemodialysis and related therapies. Renal Replacement Therapy. 2018:4:15. https://doi.org/10.1186/s41100-018-0155-x.

42. Nitta K, Masakane I, Hanafusa N, Taniguchi M, Hasegawa T, Nakai S, et al. Annual dialysis data report 2017, JSDT renal data registry. Ren Replace Ther. 2019;5:53. https://doi.org/10.1186/s41100-019-0248-1.

43. Schiffl $\mathrm{H}$. High-volume online haemodiafiltration treatment and outcome of end-stage renal disease patients: more than one mode. Int Urol Nephrol. 2020;52:1501-6.

44. Sakurai K. Biomarkers for evaluation of clinical outcomes of hemodiafiltration. Blood Purif. 2013:35(Suppl 1):64-8.

45. Sakurai K, Hosoya H, Kurihara Y, Saito T. Suitability of a1-microglobulin reduction rate as a biomarker of removal efficiency of online hemodiafiltration: a retrospective cohort study. Renal Replacement Therapy. 2021;7:10. https://doi.org/10.1186/s41100-021-00326-y.

46. Sakurai K, Saito T, Yamauchi F, Hosoya H, Kurihara Y, Kurosawa K, et al. Comparison of the effects of pre-and post-dilution on-line hemodiafiltration on the cell surface and other inflammatory markers. Nephrol Dial Transplant. 2016;31(suppl 1):i493.

47. KimST ArchivesRelease. https://www.youtube.com/user/KimSTArchivesRe lease.

48. Magnum G, Olsson M, et al. Pathological conditions involving extracellar hemoglobin: molecular mechanisms, clinical significance, and novel therapeutic opportunities for alpha(1)-microglobulin. Antioxidants Redox Signal. 2012;17(5):813-45.

49. Kristiansson A, Bergwik J, Alattar AG, Flygare J, Gram M, Hansson SR, et al. Human radical scavenger a1-microglobulin protects against hemolysis in vitro and a1-microglobulin knockout mice exhibit a macrocytic anemia phenotype. Free Radic Biol Med. 2021;162:149-59.

50. JAMREDS Study. https://rctportal.niph.go.jp/s/detail/um?trial_id=UMINO 00038457.

51. Koda Y, Aoike I, Hasegawa S, Osawa Y, Nakagawa Y, Iwabuchi F, et al. Feasibility of intermittent back-filtrate infusion hemodiafiltration to reduce intradialytic hypotension in patients with cardiovascular instability: a pilot study. Clin Exp Nephrol. 2017;21:324-32. 
52. Mineshima M, Takahashi S, Tomo T, Kawanishi H, Kawaguchi H, Minakuchi $J$, et al. A clinical significance of intermittent infusion hemodiafiltration using backfiltration of ultrapure dialysis fluid compared to hemodialysis: a multicenter randomized controlled crossover trial. Blood Purif. 2019;48:368-81

\section{Publisher's Note}

Springer Nature remains neutral with regard to jurisdictional claims in published maps and institutional affiliations.
Ready to submit your research? Choose BMC and benefit from:

- fast, convenient online submission

- thorough peer review by experienced researchers in your field

- rapid publication on acceptance

- support for research data, including large and complex data types

- gold Open Access which fosters wider collaboration and increased citations

- maximum visibility for your research: over 100M website views per year

At BMC, research is always in progress.

Learn more biomedcentral.com/submissions 